\title{
RELATIVE AGE EFFECT: A SYSTEMATIC DISCRIMINATION AGAIIST BIOLOGICALLY YOUNGER ATHLETES
}

\author{
Aristotelis Gioldasis ${ }^{\mathrm{A}, \mathrm{B}, \mathrm{C}, \mathrm{D}}$ \\ School of Physical Education and Sport Science, National and Kapodistrian University of Athens, Greece \\ ORCID: 0000-0002-5927-3949 | e-mail: giold_telis@yahoo.gr
}

\section{Evangelos Bekris ${ }^{C, D}$}

School of Physical Education and Sport Science, National and Kapodistrian University of Athens, Greece ORCID: 0000-0001-5178-0391

\author{
Athanasia Smirniotou, ${ }^{A, B, C, D}$ \\ School of Physical Education and Sport Science, National and Kapodistrian University of Athens, Greece \\ ORCID: 0000-0003-4652-6705

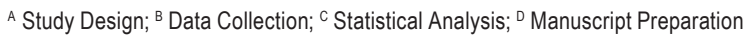

\begin{abstract}
Ahstract Physical differences associated with birth-date among athletes of the same selection year have been described as the Relative Age Effect (RAE). The aim of this study was to examine whether RAE still exists in soccer and running sport disciplines as well as to evaluate its progress among different gender, age, and sport context and if it has an effect on performance. Using official archives of the international sports' associations (World Athletics-UEFA), birthdates and performance were collected for 7,226 athletes (4,033 males; 3,198 females) who participated in soccer and running events. A chi-square test was used to assess differences between observed and expected birth date distributions. The study showed an over-representation of athletes born in the first quarter of the selection year for both soccer and running events. RAE is more obvious in younger age groups and in sports that require higher explosive speed, strength, power and anaerobic capacity such as soccer and short distance sprints. It was also found that RAE is associated with performance. In conclusion, athletes of younger age groups with greater biological age have a physical advantage in explosive sports (i.e. soccer and short distance running) that probably does not predict their future development.
\end{abstract}

Key wordls RAE, talent, soccer, running

\section{Introduction}

Within youth sports, athletes are generally assigned to groups according to their chronological age for the purpose of providing them the appropriate and equal opportunities of training and competition (Cobley, Baker, Wattie, McKenna, 2009; Kearney, Hayes, Nevill, 2018). These competitive opportunities are used for talent identification processes and can potentially provide equal learning experiences (Mohamed et al., 2009). Although, grouping 
athletes in categories according to their chronological age appears to be a practical, equitable and safe process, the research has shown that relatively older athletes within such groups are supposed to be advantaged (Smith, Weir, Till, Romann, Cobley, 2018). However, even if youngsters belong to the same chronological group they may differ markedly with respect to biological maturation (Baxter-Jones, Eisenmann, Sherar, 2005; Lloyd, Oliver, Faigenbaum, Myer, Croix, 2014). Furthermore, these differences are also heightened due to the two year chronological range that many sports use to classify young athletes into groups (Sherar, Esliger, Baxter-Jones, Tremblay, 2007). Literature review confirms this suggestion by highlighting a disproportionate number of athletes born shortly after the cut-off date of the age group compared to the ones born shortly before it. This phenomenon is defined Relative Age Effect (RAE) which refers to the asymmetry of birth distribution within each sport population.

The RAE phenomenon is observed in several team and individual sports, including soccer (Práxedes, Moreno, García-González, Pizarro, Del Villar, 2017), basketball (Arrieta, Torres-Unda, Gil, Irazusta, 2016), swimming (Nagy, Földesi, Sós, Ökrös, 2018), tennis (Gerdin, Hedberg, Hageskog, 2018), track and field (BrazoSayavera, Martinez-Valencia, Mueller, Andronikos, Martindale, 2018). The underlying causes of RAE are potentially multifactorial due to the differences in physical, physiological, cognitive, psychological and social characteristics (Smith et al., 2018). According to the maturation-selection hypothesis, relatively older athletes within the age group indicate more favorable anthropometrical and physical characteristics which may provide them with various performance advantages (Cobley et al., 2009; Lovell, Towlson, Parkin, Portas, Vaeyens, Cobley, 2015). Although the initial advantage of relatively older athletes is already known, most of the trainers strengthen the developmental advantages by providing them with greater opportunities of supplementary coaching and accessibility to higher level of competition that probably influences their progress and participation in later years (Cobley et al., 2009; Hancock, Adler, Côté, 2013). Consequently younger athletes are more likely to feel failure, frustration and finally dropout of sports and talent pools due to less sport experiences, enjoyment, rewards and success (Delorme, Chalabaev, Raspaud, 2011; Hollings, Hume, Hopkins, 2014). On the other hand, the remaining younger athletes are more likely to excel as adults and have a longer and a more successful career than their older peers (Deaner, Lowen, Cobley, 2013; McCarthy Collins, 2014).

It is clear that youths born early in the year are more experienced and physically superior than their peers who were born later (Milić, 2016). Literature review showed that as sport contexts rely on different technical, cognitive and gross motor abilities, they may show relative age effects at different trainable aspects (Kearney et al., 2018). It seems that the strength of RAE depends on sport, gender, age category and skill level factors (Cobley et al., 2009; Smith et al., 2018). In particular, although gender makes a little difference to the overall RAE distribution, it has been found that the highest level of RAE is associated with the youngest age categories in females but with the adolescence in males. This difference is probably explained by the earlier biological growth of females and their faster development in motor coordination, body control and physical characteristics (Smith et al., 2018). In total, RAE progressively increased from the child (<11 yrs) to the adolescent age (15-18 yrs) before reduced within the senior age (>18 yrs). This reduction is probably explained by several mechanisms such as higher rates of dropping out of younger athletes (Lemez, Fraser-Thomas, 2018; Penna, Campos, Gonçalves, Godinho, Lima, Prado, 2018), reduction of physical maturity differences (Cobley et al., 2009), and transfer from one sport to another depending on the compatibility of performance requirements (Baker, Cote, Abernethy, 2003). Regarding the relationship between RAE and competition level, it has been found an increased magnitude of RAE at higher competition levels (Cobley et al., 2009; Lovell et al., 2015; Romann, Cobley, 2015). As far as the association between sport 
context and RAE, it seems that technical/skill-based or weight-categorized sports were generally not associated with RAE (Albuquerque, Fukuda, Da Costa, Lopes, Franchini, 2016; Côté, MacDonald, Baker, Abernethy, 2006; Delorme, Raspaud, 2009). On the other hand RAE is extremely high in team sports, where athletes' comparisons appear on the field of play, as well as in sports emphasizing on individual anthropometric and physical differences characteristics. Therefore greater RAE occurs in physical demanded sports such as basketball, volleyball, soccer, track and field (Cobley et al., 2009; Romann, Fuchslocher, 2014; Smith et al., 2018).

It is obvious that RAE occurs mostly in physical based sports in which biological maturation may affect performance. This phenomenon frequently leads on increases of dropping out rates and a reduction of potentially youth talented athletes, which in long term contributes to a performance reduction of top level and national teams (Pizzuto, Bonato, Vernillo, La Torre, Piacentini, 2017; Jiménez, Pain, 2008). Furthermore, in order to monitor the youths' development, trainers and coaches have to take into consideration the performance characteristics of each sport so as to identify strengths and weaknesses of their athletes, prescribe and evaluate training, as well as to select the real talents instead of the more mature (de Freitas, Werneck, de Souza, de Castro, Figueiredo, de Lima, 2020). In particular, soccer and running are commonly considered as physically demanded sports that coaches evaluate similar characteristics such as physical size, strength, flexibility, coordination, speed, aerobic and anaerobic capacity to identify potentially future talents (Furley, Memmert, 2016; Henriksen, Stambulova, Roessler, 2010; Hollings et al., 2014; Kruger, Pienaar, 2009; Pandi, 2018; Sarmento, Anguera, Pereira, Araújo, 2018). Although running requires higher individual physical development due to the single attributes it includes (i.e. sprinting), the majority of RAEs' studies focus on team sports (Cobley et al., 2009). Therefore, the purpose of the current study was to determine RAE prevalence and magnitudes across soccer and running and its relationship with performance. Furthermore, in order to identify moderators of RAE magnitude, identified samples were examined in subgroups according to gender, age, and sport discipline. Based on existing literature, we hypothesized that RAE was prevalent across both soccer and running with a greater magnitude in physically demanded running disciplines. RAE was also expected to be stronger within male population but lower in older age groups. As the evidence relating to the relationship between RAE and performance within sport disciplines is equivocal, no predictions were made.

\section{Material and Methods}

\section{Participants}

Data were acquired from the official web-sites of World Athletics and UEFA. These databases provide information about athletes' performance and age as well as teams' performance. Participants were collected from different individual and team sport events, which represent the core athletic disciplines, such as running (100 m, $800 \mathrm{~m}, 1,500 \mathrm{~m}, 3,000 \mathrm{~m}, 5,000 \mathrm{~m}, 10,000 \mathrm{~m}$, hurdles), and soccer. In total the researchers recorded the date of births of 7,226 athletes ( $n=4,033$ males; 3,198 females) who had been selected to participate in IAAF world championships throughout 2011-2018 and UEFA 2020 European championships. The participants who were recorded derived from U-18 and U-20 running events as well as U-17 and U-19 soccer events. As previously suggested, athletes who ranked in multiple events were only counted within the event in which they ranked most highly (Kearney et al., 2018). Furthermore, although an informed consent was not needed as the reported data were available online, the researchers reported them anonymously. 


\section{Procedures}

Athletes were classified by birthdates according to the international cut-off date of $1^{\text {st }}$ January. Although, most of the athletes who are selected to participate in youth national teams organized within a one or two-year difference for each age band, in soccer some were even younger. For each of the two age categories, the birth month of each athlete was recorded within a three month birth quarter (Q1: January, February, and March; Q2: April, May, and June; Q3: July, August, and September; Q4: October, November, and December; Q5: January, February, and March of the next years etc). Performance was evaluated by qualification, semi-final and final ranking for runners individually and by final ranking, total points, and qualification attainment for soccer teams. The study was conducted according to the Declaration of Helsinki, and the protocol was approved by the University Ethics Committee of the School of Physical Education and Sport Science before the beginning of this study.

\section{Data analysis}

Frequencies were obtained for each birth quartile to record the total distribution of the sample (Brazo-Sayavera et al., 2018).Then, chi-square test was used to assess differences between observed and expected relative age distribution according to gender and age category. Linear regression analyses using performance as the dependent variable considering gender, age, and disciplines was performed. Correlation coefficients ( $r$ ), adjusted coefficients of determination $\left(R^{2}\right)$, standard estimate errors (SEE) and analyses of variance were calculated. Finally, residuals were assessed for normality, independence, linearity, and homoscedasticity, whereas all statistical assumptions for linear regression were met. The magnitude of the correlation coefficients $(r)$ was examined according to Hopkins (2006) as follows: very small $<0.1$, small $0.1-0.3$, moderate $0.3-0.5$, large $0.5-0.7$, very large $0.7-0.9$, nearly perfect $>0.9$ and perfect $r=1$. The statistical package IBM SPSS v. 23 was used for analysis and the level of significance was set at $p<0.05$.

\section{Results}

A total of 7469 participants were recorded of which 243 excluded (3.25\%) due to missing data. The following table presents sample details of the remaining 7,226 participants (Table 1).

Table 1. Sample details according to age, gender and sport

\begin{tabular}{|c|c|c|c|c|c|c|c|c|c|c|c|}
\hline \multirow[b]{2}{*}{ Age } & \multirow[b]{2}{*}{ Gender } & \multicolumn{9}{|c|}{ Sport } & \multirow[b]{2}{*}{ Tota } \\
\hline & & $100 \mathrm{~m}$ & $\begin{array}{c}100 / 110 \mathrm{~m} \\
\text { hurdles }\end{array}$ & $\begin{array}{l}400 \mathrm{~m} \\
\text { hurdles }\end{array}$ & $800 \mathrm{~m}$ & $1,500 \mathrm{~m}$ & $3,000 \mathrm{~m}$ & $5,000 \mathrm{~m}$ & $10,000 \mathrm{~m}$ & $\begin{array}{c}\text { soccer } \\
\text { U-17/U-19 }\end{array}$ & \\
\hline \multirow{2}{*}{ U-18 } & males & 286 & 151 & 161 & - & - & - & - & - & 894 & 1492 \\
\hline & females & 238 & 141 & 122 & - & - & - & - & - & 758 & 1259 \\
\hline \multirow{2}{*}{ U-20 } & males & 215 & 222 & 197 & 324 & 271 & 105 & 87 & 95 & 1025 & 2541 \\
\hline & females & 188 & 170 & 159 & 269 & 211 & 121 & 65 & - & 751 & 1939 \\
\hline Total & & 927 & 684 & 639 & 593 & 482 & 226 & 152 & 95 & 3428 & 7226 \\
\hline
\end{tabular}

Figures 1 and 2 show the birth-date proportions within quartiles of all the participants according to their gender and age category. In particular, Figure 1 shows that: $37 \%$ males and $20 \%$ females of the U-17 or U-18 sample born in the $1^{\text {st }}$ quartile of two years; $25 \%$ males and $18 \%$ females of the U-17 or U-18 sample born in the $2^{\text {nd }}$ quartile of two 
years; $16 \%$ males and $16 \%$ females of the $U-17$ or $U-18$ sample born in the $3^{\text {rd }}$ quartile of two years; $11 \%$ males and $12 \%$ females of the U-17 or U-18 sample born in the $4^{\text {th }}$ quartile of two years; $5 \%$ males and $11 \%$ females of the $\mathrm{U}-17$ or $\mathrm{U}-18$ sample born in the $5^{\text {th }}$ quartile of two years; $4 \%$ males and $10 \%$ females of the U-17 or U-18 sample born in the $6^{\text {th }}$ quartile of two years; $1 \%$ males and $7 \%$ females of the $\mathrm{U}-17$ or $\mathrm{U}-18$ sample born in the $7^{\text {th }}$ quartile of two years; $2 \%$ males and $6 \%$ females of the $U-17$ or U-18 sample born in the $8^{\text {th }}$ quartile of two years (Figure 1 ).

Similarly, Figure 2 shows that: $25 \%$ males and $15 \%$ females of the U-19 or U-20 sample born in the $1^{\text {st }}$ quartile of four years; $20 \%$ males and $13 \%$ females of the U-19 or U-20 sample born in the $2^{\text {nd }}$ quartile of four years; $14 \%$ males and $12 \%$ females of the U-19 or U-20 sample born in the $3^{\text {rd }}$ quartile of four years; $11 \%$ males and $10 \%$ females of the U-19 or U-20 sample born in the $4^{\text {th }}$ quartile of four years; $10 \%$ males and $13 \%$ females of the U-19 or U-20 sample born in the $5^{\text {th }}$ quartile of four years; $7 \%$ males and $11 \%$ females of the U-19 or U-20 sample born in the $6^{\text {th }}$ quartile of four years; $6 \%$ males and $9 \%$ females of the U-19 or U-20 sample born in the $7^{\text {th }}$ quartile of four years; $4 \%$ males and $8 \%$ females of the U-19 or U-20 sample born in the $8^{\text {th }}$ quartile of four years; whereas the rest $4 \%$ males and $8 \%$ females of the U-19 or U-20 sample born in the following two years (Figure 2).

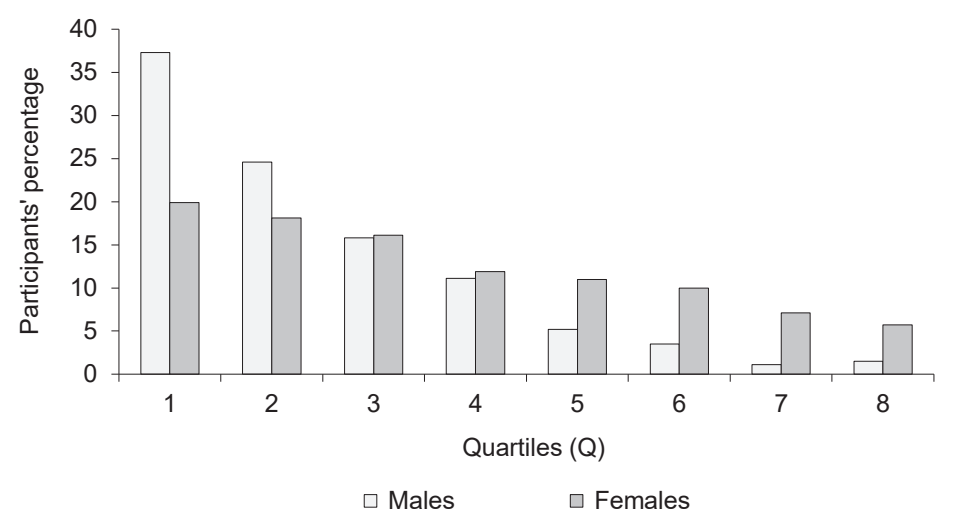

Figure 1. Birth date proportions within quartiles and gender for U-17 or U-18 participants

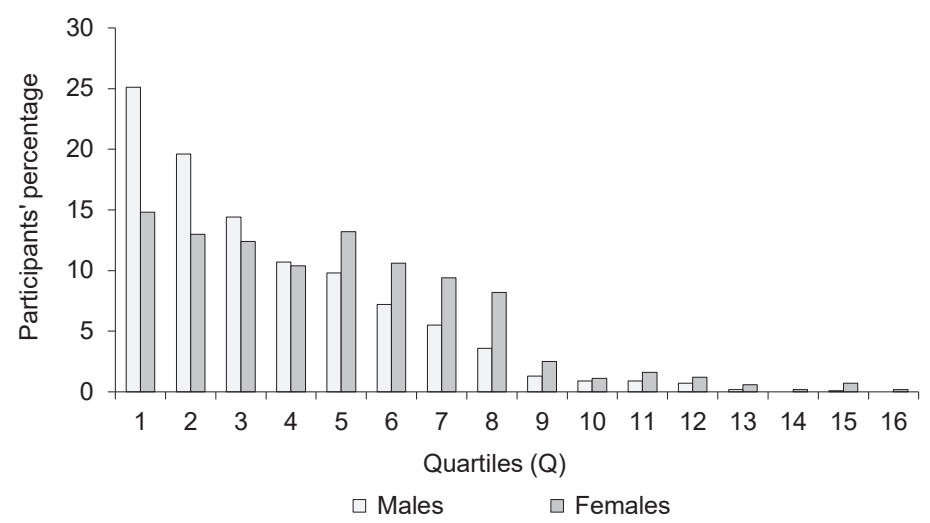

Figure 2. Birth date proportions within quartiles and gender for U-19 or U-20 participants 
Table 2 shows the quartile distributions and chi-squares subdivided according to gender, age category, and sport discipline. The results showed significant differences between quartiles for both U-18 and U-20 $100 \mathrm{~m}$ males and females (U-18 males: $X^{2}=154.84, p=0.000 ; U-18$ females: $X^{2}=24.19, p=0.001 ; U-20$ males: $X^{2}=104.40$, $p=0.000$; and $U-20$ females: $\left.X^{2}=66.04, p=0.000\right), U-18$ and $U-20110 \mathrm{~m}$ hurdles males and $100 \mathrm{~m}$ hurdles females (U-18 males: $X^{2}=128.68, p=0.000 ; U-18$ females: $X^{2}=39.82, p=0.000 ; U-20$ males: $X^{2}=144.58, p=0.000$; and U-20 females: $\left.\chi^{2}=100.12, p=0.000\right), U-18$ and U-20 400 m hurdles males and females (U-18 males: $X^{2}=8.21$, $p=0.000$; U-18 females: $X^{2}=46.79, p=0.000 ; U-20$ males: $X^{2}=136.26, p=0.000$; and U-20 females: $X^{2}=113.16$, $p=0.000), U-20800 \mathrm{~m}$ males and females (U-20 males: $X^{2}=87.40, p=0.000 ; U-20$ females: $X^{2}=76.02, p=0.000$ ), U-20 1500 m males and females (U-20 males: $X^{2}=114.44, p=0.000 ; U-20$ females: $\left.X^{2}=54.79, p=0.000\right), U-20$ $3,000 \mathrm{~m}$ males $\left(X^{2}=73.67, p=0.000\right), U-205,000 \mathrm{~m}$ males and females ( $U-20$ males: $X^{2}=40.76, p=0.000$; U-20 females: $\left.X^{2}=27.86, p=0.000\right), U-2010,000$ m males $\left(X^{2}=55.84, p=0.000\right)$, but not significant relative age distribution for $U-203,000 \mathrm{~m}$ females $\left(X^{2}=10.28, p=0.591\right)$. Finally, the results showed significant differences between quartiles for both $U-17$ and $U-19$ soccer males and females (U-17 males: $X^{2}=1074.81, p=0.000 ; U-17$ females: $X^{2}=112.63, p=0.000 ; U-19$ males: $X^{2}=1,321.98, p=0.000$; and U-19 females: $X^{2}=381.78, p=0.000$ ) (Table 2).

A significant regression equation was found for $100 \mathrm{~m}$ hurdles $\mathrm{U}-18$ female athletes $\left(F_{(1,139)}=4.533\right.$, $p=0.035$ ), with and $R^{2}$ of 0.032 . Participants' predicted performance is equal to $2.818+0.072$ (age) ranking when age is measured in quartiles. Participant's performance reduced 0.072 ranking for each quartile of age. A significant regression equation was found for $100 \mathrm{~m} \mathrm{U}-20$ male athletes $\left(F_{(1,212)}=2.679, p=0.103\right)$, with and $R^{2}$ of 0.012 . Participants' predicted performance is equal to $3.201+0.031$ (age) ranking when age is measured in quartiles. Participant's performance reduced .031 ranking for each quartile of age. A significant regression equation was found for $100 \mathrm{~m} \mathrm{U}-20$ female athletes $\left(F_{(1,186)}=4.401, p=0.037\right)$, with and $R^{2}$ of 0.023 . Participants' predicted performance is equal to $3.038+0.037$ (age) ranking when age is measured in quartiles. Participant's performance reduced 0.037 ranking for each quartile of age. A significant regression equation was found for $100 \mathrm{~m}$ hurdles $U-20$ male athletes $\left(F_{(1,220)}=2.875, p=0.091\right)$, with and $R^{2}$ of 0.013 . Participants' predicted performance is equal to $3.215+0.037$ (age) ranking when age is measured in quartiles. Participant's performance reduced 0.037 ranking for each quartile of age. A significant regression equation was found for $1,500 \mathrm{~m} \mathrm{U}-20$ male athletes $\left(F_{(1,149)}=7.858\right.$, $p=0.006$ ), with and $R^{2}$ of 0.050 . Participants' predicted performance is equal to $2.798+0.052$ (age) ranking when age is measured in quartiles. Participant's performance reduced 0.052 ranking for each quartile of age. A significant regression equation was found for $5,000 \mathrm{~m} \mathrm{U}-20$ male athletes $\left(F_{(1,85)}=7.539, p=0.007\right)$, with and $R^{2}$ of 0.081 . Participants' predicted performance is equal to $2.008+0.028$ (age) ranking when age is measured in quartiles. Participant's performance reduced 0.028 ranking for each quartile of age. A significant regression equation was found for $5,000 \mathrm{~m} \mathrm{U}-20$ female athletes $\left(F_{(1,63)}=2.395, p=0.127\right)$, with and $R^{2}$ of 0.037 . Participants' predicted performance is equal to $1.942+0.023$ (age) ranking when age is measured in quartiles. Participant's performance reduced 0.023 ranking for each quartile of age. A significant regression equation was found for $10,000 \mathrm{~m} \mathrm{U-20}$ male athletes $\left(F_{(1,93)}=2.017, p=0.006\right)$, with and $R^{2}$ of 0.077 . Participants' predicted performance is equal to $2.017+0.031$ (age) ranking when age is measured in quartiles. Participant's performance reduced .031 ranking for each quartile of age. A significant regression equation was found for $800 \mathrm{~m} \mathrm{U}-20$ male athletes $\left(F_{(1,167)}=3.041\right.$, $p=0.083$ ), with and $R^{2}$ of 0.018 . Participants' predicted performance is equal to $1.388+0.023$ (age) ranking when age is measured in quartiles. Participant's performance reduced 0.023 ranking for each quartile of age. 


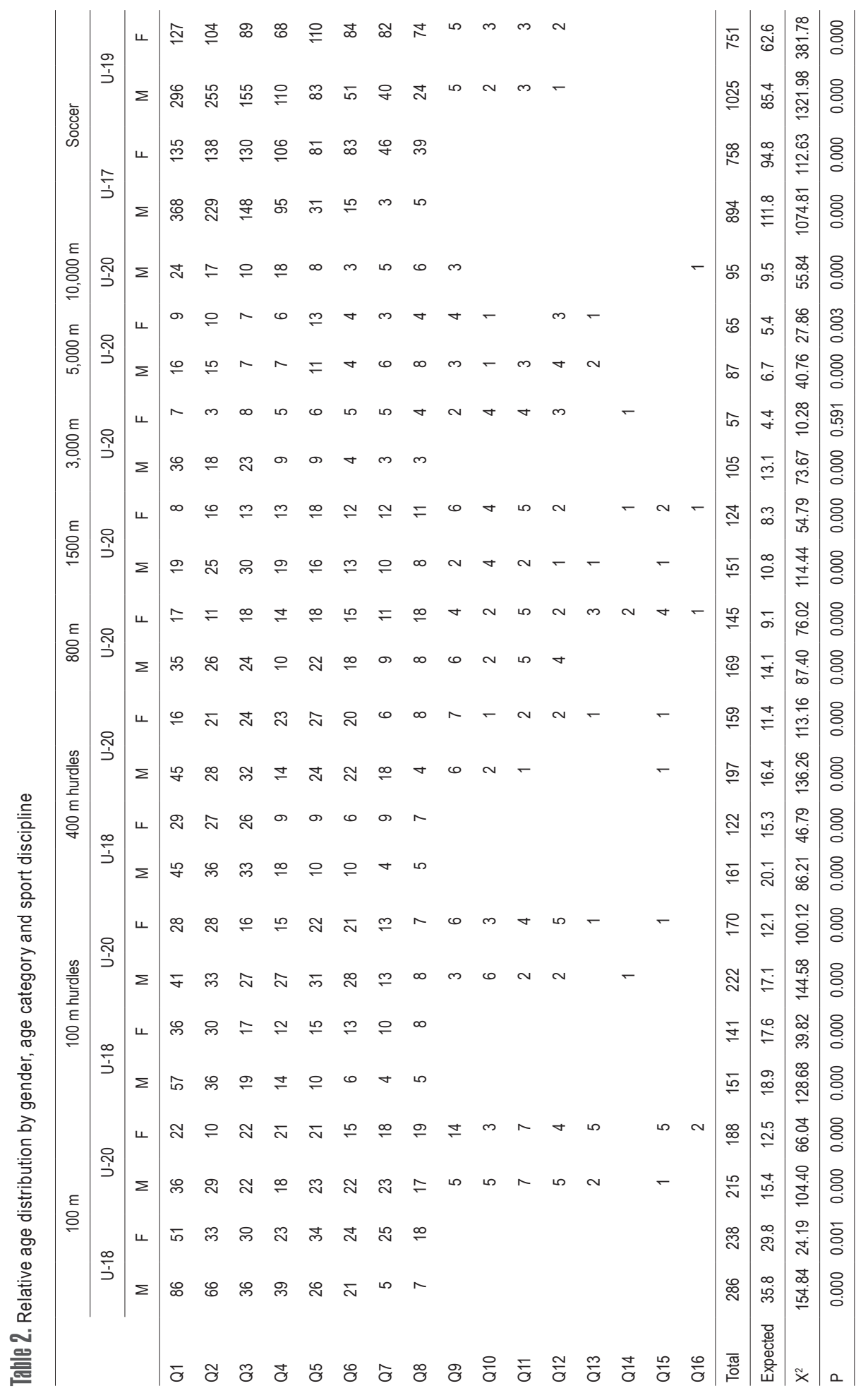


Table 3. Performance distribution according to birth quartile

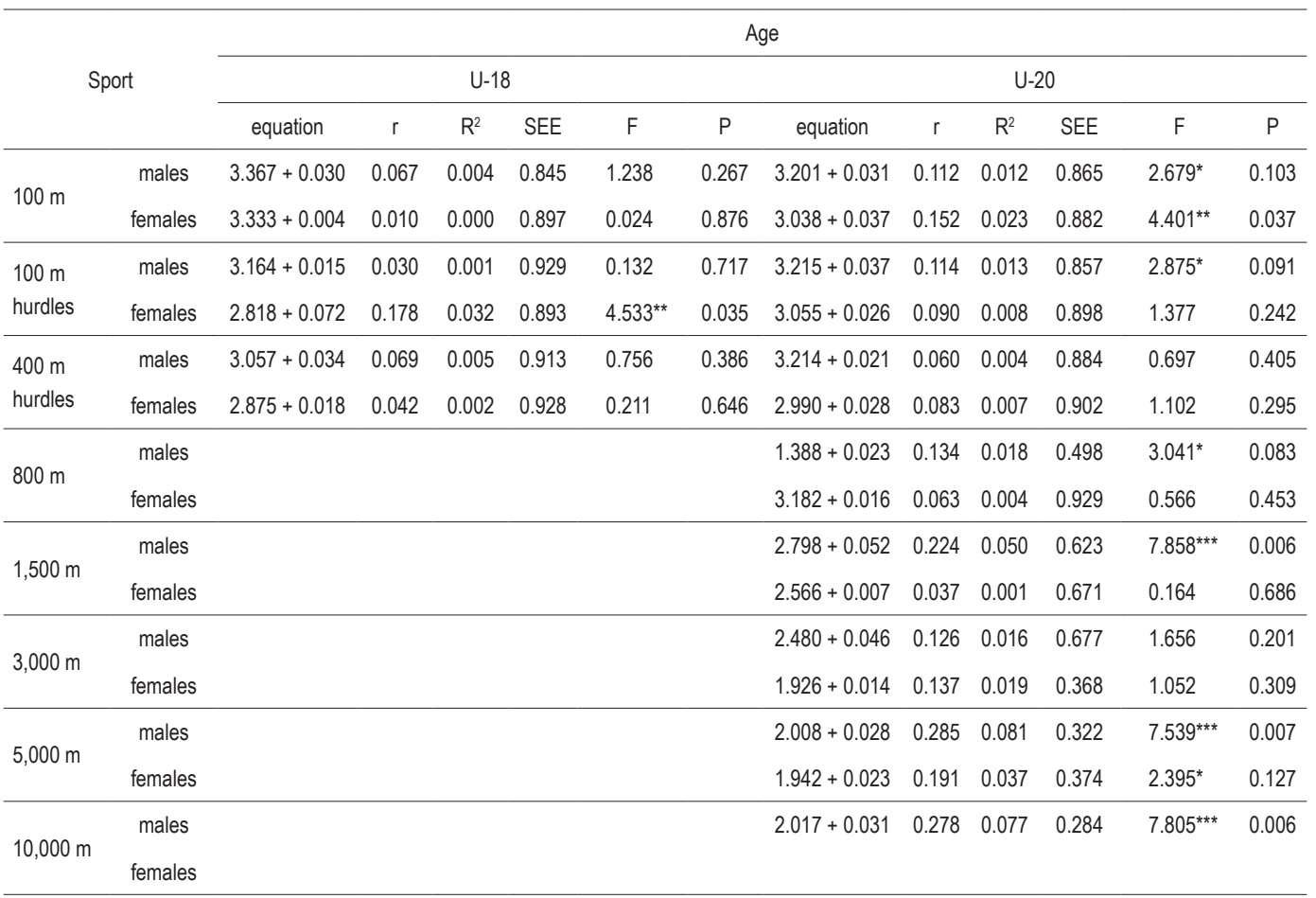

${ }^{*} p<0.10 ;{ }^{* *} p<0.05 ;{ }^{* * *} p<0.01$.

The following table shows the relationship between relative age effect measured by the medians of each team with team performance measured by ranking, points, and qualification. Statistical testing of this relationship revealed significant correlations for U-17 male players between rank, points and qualification with RAE medians (Spearman's $r=0.306, p=0.038 ; r=-0.379, p=0.009$; and $r=0.317, p=0.032$, respectively), and a linear regression analysis $\left(F_{(1,44)}=5.118, p=0.029 ; F_{(1,44)}=6.615, p=0.014 ; F_{(1,44)}=5.753, p=0.021\right.$, respectively) with $R^{2}$ of $0.104 ; 0.131 ; 0.116$ respectively. Teams' predicted performance is equal to $1.103+0.670 ; 8.292+1.934 ; 0.835+0.329$ revealing that having a median earlier quartile is associated with an advantage of 0.670 ranks, 1.934 points, and 0.329 qualification. Statistical testing of this relationship revealed significant correlations for $\mathrm{U}-17$ female players between rank, points and qualification with RAE medians (Spearman's $r=0.403, p=0.009 ; r=-0.346, p=0.027$; and $r=0.391$, $p=0.011$, respectively), and a linear regression analysis $\left(F_{(1,39)}=7.097, p=0.011 ; F_{(1,39)}=4.541, p=0.039 ; F_{(1,39)}\right.$ $=6.419, p=0.015$, respectively) with $R^{2}$ of $0.154 ; 0.104 ; 0.141$ respectively. Teams' predicted performance is equal to $0.877+0.462 ; 8.126+1.085 ; 0.791+0.200$ revealing that having a median earlier quartile is associated with an advantage of 0.462 ranks, 1.085 points, and 0.200 qualification. Statistical testing of this relationship revealed significant correlations for $\mathrm{U}-19$ male players between rank, points and qualification with RAE medians (Spearman's $r=0.353, p=0.010 ; r=-0.389, p=0.004 ;$ and $r=0.256, p=0.067$, respectively), and a linear regression analysis $\left(F_{(1,50)}=7.149, p=0.010 ; F_{(1,50)}=9.445, p=0.003 ; F_{(1,50)}=2.983, p=0.090\right.$, respectively) with $R^{2}$ of 0.125 ; 
$0.159 ; 0.256$ respectively. Teams' predicted performance is equal to $1.452+0.407 ; 7.466+1.233 ; 1.186+0.122$ revealing that having a median earlier quartile is associated with an advantage of 0.407 ranks, 1.233 points, and 0.122 qualification. Statistical testing of this relationship revealed significant correlations for U-19 female players between rank, points and qualification with RAE medians (Spearman's $r=0.404, p=0.012 ; r=-0.285, p=0.083$; and $r=0.292, p=0.076$, respectively), and a linear regression analysis $\left(F_{(1,36)}=6.893, p=0.013 ; F_{(1,36)}=3.568\right.$, $p=0.067 ; F_{(1,36)}=3.236, p=0.080$, respectively) with $R^{2}$ of $0.161 ; 0.090 ; 0.082$ respectively. Teams' predicted performance is equal to $0.647+0.331 ; 8.609+0.725 ; 0.821+0.123$ revealing that having a median earlier quartile is associated with an advantage of 0.331 ranks, 0.725 points, and 0.123 qualification (Table 4).

Table 4. Impact of the RAE on Performance variables

\begin{tabular}{|c|c|c|c|c|c|c|c|c|c|c|c|c|c|}
\hline \multirow{3}{*}{ Soccer } & & \multicolumn{12}{|c|}{ Age } \\
\hline & & \multicolumn{6}{|c|}{ U-17 } & \multicolumn{6}{|c|}{ U-19 } \\
\hline & & Equation & $r$ & $\mathrm{R}^{2}$ & SEE & $\mathrm{F}$ & $P$ & Equation & $\mathrm{R}$ & $\mathrm{R}^{2}$ & SEE & $\mathrm{F}$ & $P$ \\
\hline \multirow{2}{*}{ Ranking } & males & $1.103+0.670$ & 0.323 & 0.104 & 1.030 & 5.118 & 0.029 & $1.452+0.407$ & 0.354 & 0.125 & 1.067 & 7.149 & 0.010 \\
\hline & females & $0.877+0.462$ & 0.392 & 0.154 & 1.044 & 7.097 & 0.011 & $0.647+0.331$ & 0.401 & 0.161 & 0.862 & 6.893 & 0.013 \\
\hline \multirow{2}{*}{ Points } & males & $8.292+1.934$ & 0.362 & 0.131 & 2.616 & 6.615 & 0.014 & $7.466+1.233$ & 0.399 & 0.159 & 2.814 & 9.445 & 0.003 \\
\hline & females & $8.126+1.085$ & 0.323 & 0.104 & 3.066 & 4.541 & 0.039 & $8.609+0.725$ & 0.300 & 0.090 & 2.629 & 3.568 & 0.067 \\
\hline \multirow{2}{*}{ Qualification } & males & $0.835+0.329$ & 0.340 & 0.116 & .477 & 5.753 & 0.021 & $1.186+0.122$ & 0.237 & 0.256 & 0.495 & 2.983 & 0.090 \\
\hline & females & $0.791+0.200$ & 0.376 & 0.141 & .475 & 6.419 & 0.015 & $0.821+0.123$ & 0.287 & 0.082 & 0.467 & 3.236 & 0.080 \\
\hline
\end{tabular}

\section{Discussion}

Given the necessity to understand and isolate the mechanisms causing RAE, and to suggest appropriate solutions to eliminate this diachronic phenomenon the researchers examined relative age effect in two high physical demanded individual and team sport contexts and its relationship with performance. Although past research has long documented the need for changes in the registration of players in sports so as to reduce the effects of RAE, the current findings indicate that this issue still remains unsolved.

\section{RAE magnitude and age}

The analyses in our study showed that greater RAEs were found at U-17-U-18 age category compared to the U-19-U-20 category. The higher RAE of younger athletes has been corroborated by previous studies which suggest that it weakens across time from U-18 to U-20 in running (Brazo-Sayavera et al., 2018; Hollings et al., 2014) and from U-17 to U-19 in soccer (Helsen, Van Winckel, Williams, 2005) sport contexts. The reduction of RAE at the older age category is difficult to explain, with various mechanisms possibly affecting RAE in the early stages of commitment but reducing during the later years. In particular, differences due to physical maturity become redundant at later development stages, allowing players of older age groups to perform on a more equal way (Cobley et al., 2009). In addition, parents, coaches and/or athletes all amplify the RAE at a different way especially in younger ages (Hancock, Ste-Marie, Young, 2013). For example, parents may affect RAE through enrolling in sports relatively 
older players whereas coaches might place greater expectations and advantage to relatively older athletes (Brustio et al., 2019). Finally, the larger RAE in U-18 group of track and field athletes might be due to the unique scheduling of World Athletics championships. Specifically, older athletes of U-18 group have an advantage that reverses when they become the younger athletes of the U-20 group the following year. Respectively, the disadvantaged younger $\mathrm{U}-18$ group athletes enjoy the advantage of competing at the U-20 group three years later. These reversals possibly reduce the RAE of older age categories (Hollings et al., 2014).

\section{RAE magnitude and gender}

Moreover, an overall RAE was evident across all participants, with males showing a stronger effect than female athletes in both track and field sport disciplines and soccer. This finding has been supported by studies which revealed that RAE is evident, albeit is less pronounced in female events (Hollings et al., 2014; SaavedraGarcía, Gutiérrez-Aguilar, Sa-Marques, Fernández-Romero, 2016). Several speculative explanations support this finding such as the popularity of sports and the consequent more chances to be selected or/and self-selected (Till et al., 2010), or early maturation reasons (Brazo-Sayavera et al., 2018). More specifically, according to maturation selection hypothesis (Tanner, 1981), females tend to experience puberty earlier than males. It is well established that after adolescence strength is still increasing in males but tends to be stabilized in females due to hormone effects (Papaiakovou et al., 2009). Females are presumably closer to physical maturity than males and probably gain less than males from a year difference (Hollings et al., 2014). Furthermore, genetic reasons (i.e. genu valgum, tendon viscoelastic properties) which are more prominent after puberty might influence movement coordination and sprint speed of females (Hewett, Myer, Ford, 2004; Kubo, Kanehisa, Fukunaga, 2003; Papaiakovou et al., 2009).

\section{RAE magnitude and spopt discipline}

More specifically, RAE was stronger for sprinting events and soccer than for middle distance events finding that is also supported by past studies (Brustio et al., 2019; Kearney et al., 2018).This finding may suggest that endurance capacity was less affected by the relative age of athletes. In particular, from athletic context the disciplines of $100 \mathrm{~m}$ sprinting, 100/110 m and $400 \mathrm{~m}$ hurdles were more affected. All these disciplines require strength, speed and a developed muscle mass (Hollings et al., 2014). This may suggest that relatively older athletes might be advantaged by more developed anthropometric characteristics which produce greater levels of strength and speed (Brustio et al., 2019; Hollings et al., 2014; Kearney et al., 2018). Also in soccer, players may be benefited more by speed and strength abilities than by endurance capacity. Consequently, sports that require anaerobic capacity, as well as explosive speed, strength and power, such as short distance runs and soccer, follow similar training strategies, and influenced more by RAE.

\section{RAE magnitude and performance}

Regarding the relationship between performance and RAE the analyses showed that RAE predicted performance in several sport disciplines. In particular, within U-18 age category, the relatively older females showed significantly greater performance than younger athletes in $100 \mathrm{~m}$ hurdles. Correspondingly, within U-20 age category relatively older males showed greater performance than their younger counterparts in $100 \mathrm{~m}$, $110 \mathrm{~m}$ hurdles, $800 \mathrm{~m}, 1,500 \mathrm{~m}, 5,000 \mathrm{~m}$ and 10,000 m. Similarly, U-20 relatively older females showed greater performance than younger athletes in $100 \mathrm{~m}$ and $5,000 \mathrm{~m}$ disciplines. Generally, literature review supports our 
findings about the relationship between RAE and track and field sports (Brustio et al., 2019; Romann, Cobley, 2015). Although RAE is not so obvious in older age category such as in younger, it affects more players' performance in the older one. It can probably be explained by several social, physiological and psychological factors which might be affected by physical differences across the previous years. In general, although at this age the physical differences have disappeared, older players have already experienced superior training guidance and conditions which benefited various motor-physical skills, such as coordination, balance, strength and speed. Furthermore, they experienced greater success, and, they consequently have higher levels of competence and intrinsic motivation than their younger counterparts. Adding that drop-out rate was higher for relatively younger athletes we conclude that the combination of these indices confer an effect on performance (Cobley et al., 2009; MacDonald, Baker, 2013). Regarding soccer, the results showed a significant relationship between RAE and performance indicators taken as final ranking, total points, and qualification status. In particular, there was a significant relationship between RAE and all the performance indicators of both U-17 males and females. Similarly, in U-19 age category there was a significant relationship between RAE and ranking in both males and females, as well as between RAE and total points of male soccer players. Only the indicators of total points for females as well as qualification status for both males and females failed to indicate a significant relationship with RAE. Current findings support past research that confirmed the relationship between RAE and performance in U-17 elite soccer players (Augste, Lames, 2011). Although achieving success in team sports is affected by several variables' interference it seems that physical maturity consist a crucial factor that benefits team performance. Similarly to individual sports, although the physical differences among players have been eliminated in older age categories, relatively older players have already taken advantage compared to younger ones (Costa, Albuquerque, Garganta, 2012; Delorme, Boiché, Raspaud, 2010).

The critical question is how this preference for early born youngsters could be changed and if that contributes to greater success. Researchers have proposed several solutions to address RAEs, including rotating cut-off dates, shorter age categories bandwidths, physical and/or maturation classification schemes and educating trainers, coaches and parents (Andronikos, Elumaro, Westbury, Martindale, 2016; Cumming, Lloyd, Oliver, Eisenmann, Malina, 2017; Haycraft, Kovalchik, Pyne, Larkin, Robertson, 2018). Furthermore, regarding sprinting events, it has been suggested the application of corrective adjustments to youth results so as to remove RAE from top rankings (Cobley et al., 2019; Romann, Cobley, 2015). However, as long as there is no agreement for organizational changes against RAE, coach and parental education seems the recommended solution. Based on current findings, future research is suggested to further examine how a limitation of birthdates on the number of athletes that participate in sport events (i.e. $25 \%$ per birth semester) would reduce RAE. Furthermore, still a question exists that is if the biologically older athletes differ also in technical, tactical and cognitive characteristics.

\section{Conclusion}

In conclusion, RAE was evident within the majority of subpopulations of running sport disciplines and soccer. The results showed that selecting athletes with a higher relative age benefits individual and team success in competition against other athletes or teams. Thus it is obvious that trainers and coaches tend to prefer relative older athletes who are probably physically more mature at the time of selection. However, talent identification systems aim to promote the most promising athletes at adult age which is more important than the temporary success at younger ages. Sports should be considered as a long-term talent development process whereas winning constitutes a short term temporal goal which is frequently set by environmental factors, such as social agents 
including parents, coaches and athletes who are propagating RAE. Thus, trainers and coaches should focus to give equal opportunities to athletes to compete and increase the commitment for a long and successful career in sports.

\section{Referencences}

Albuquerque, M.R., Fukuda, D.H., Da Costa, V.T., Lopes, M.C., Franchini, E. (2016). Do weight categories prevent athletes from the relative age effect? A meta-analysis of combat sports. Sport Sciences for Health, 12 (2), 133-139.

Arrieta, H., Torres-Unda, J., Gil, S.M., Irazusta, J. (2016). Relative age effect and performance in the U-16, U-18 and U-20 European Basketball Championships. Journal of Sports Sciences, 34 (16), 1530-1534.

Augste, C., Lames, M. (2011). The relative age effect and success in German elite U-17 soccer teams. Journal of Sports Sciences, 29 (9), 983-987.

Andronikos, G., Elumaro, A.I., Westbury, T., Martindale, R.J. (2016). Relative age effect: implications for effective practice. Journal of Sports Sciences, 34 (12), 1124-1131.

Baker, J., Cote, J., Abernethy, B. (2003). Sport-specific practice and the development of expert decision-making in team ball sports. Journal of Applied Sport Psychology, 15 (1), 12-25.

Baxter-Jones, A.D., Eisenmann, J.C., Sherar, L.B. (2005). Controlling for maturation in pediatric exercise science. Pediatric Exercise Science, 17 (1), 18-30.

Brazo-Sayavera, J., Martinez-Valencia, M.A., Mueller, L., Andronikos, G., Martindale, R.J. (2018). Relative age effects in international age group championships: A study of Spanish track and field athletes. PloS one, 13 (4).

Brustio, P.R., Kearney, P.E., Lupo, C., Ungureanu, A.N., Mulasso, A., Rainoldi, A., Boccia, G. (2019). Relative age influences performance of world-class track and field athletes even in the adulthood. Frontiers in Psychology, 10.

Cobley, S., Baker, J., Wattie, N., McKenna, J. (2009). Annual age-grouping and athlete development. Sports Medicine, 39 (3), $235-256$.

Cobley, S., Abbott, S., Eisenhuth, J., Salter, J., McGregor, D., Romann, M. (2019). Removing relative age effects from youth swimming: The development and testing of corrective adjustment procedures. Journal of Science and Medicine in Sport, 22 (6), 735-740.

Côté, J., MacDonald, D.J., Baker, J., Abernethy, B. (2006). When "where" is more important than "when": Birthplace and birthdate effects on the achievement of sporting expertise. Journal of Sports Sciences, 24 (10), 1065-1073.

Cumming, S.P., Lloyd, R.S., Oliver, J.L., Eisenmann, J.C., Malina, R.M. (2017). Bio-banding in sport: applications to competition, talent identification, and strength and conditioning of youth athletes. Strength \& Conditioning Journal, 39 (2), 34-47.

Costa, I.T.D., Albuquerque, R.M., Garganta, J. (2012). Relative age effect in Brazilian soccer players: a historical analysis. International Journal of Performance Analysis in Sport, 12 (3), 563-570.

Deaner, R.O., Lowen, A., Cobley, S. (2013). Born at the wrong time: Selection bias in the NHL draft. PLoS One, 8 (2).

de Freitas, J.V., Werneck, F.Z., de Souza, R.S., de Castro, P.H.C., Figueiredo, A.J., de Lima, J.R.P. (2020). Maturation, morphological, motor and technical characteristics of under 16 female track and field athletes. Brazilian Journal of Kinanthropometry and Human Performance, 22, 68128.

Del Campo, D.G.D., Vicedo, J.C.P., Villora, S.G., Jordan, O.R.C. (2010). The relative age effect in youth soccer players from Spain. Journal of Sports Science \& Medicine, 9 (2), 190.

Delorme, N., Boiché, J., Raspaud, M. (2010). Relative age effect in female sport: a diachronic examination of soccer players. Scandinavian Journal of Medicine \& Science in Sports, 20 (3), 509-515.

Delorme, N., Chalabaev, A., Raspaud, M. (2011). Relative age is associated with sport dropout: evidence from youth categories of French basketball. Scandinavian Journal of Medicine \& Science in Sports, 21 (1), 120-128.

Delorme, N., Raspaud, M. (2009). Is there an influence of relative age on participation in non-physical sports activities? The example of shooting sports. Journal of Sports Sciences, 27 (10), 1035-1042.

Furley, P., Memmert, D. (2016). Coaches' implicit associations between size and giftedness: implications for the relative age effect. Journal of Sports Sciences, 34 (5), 459-466.

Gerdin, G., Hedberg, M., Hageskog, C. A. (2018). Relative age effect in Swedish male and female tennis players born in 19982001. Sports, 6 (2), 38.

Hancock, D.J., Adler, A.L., Côté, J. (2013). A proposed theoretical model to explain relative age effects in sport. European Journal of Sport Science, 13 (6), 630-637. 
Hancock, D.J., Ste-Marie, D.M., Young, B.W. (2013). Coach selections and the relative age effect in male youth ice hockey. Research Quarterly for Exercise and Sport, 84 (1), 126-130.

Haycraft, J.A., Kovalchik, S., Pyne, D.B., Larkin, P., Robertson, S. (2018). The influence of age-policy changes on the relative age effect across the Australian Rules football talent pathway. Journal of Science and Medicine in Sport, 21 (10), 1106-1111.

Helsen, W.F., Van Winckel, J., Williams, A.M. (2005). The relative age effect in youth soccer across Europe. Journal of Sports Sciences, 23 (6), 629-636.

Henriksen, K., Stambulova, N., Roessler, K.K. (2010). Successful talent development in track and field: considering the role of environment. Scandinavian Journal of Medicine \& Science in Sports, 20, 122-132.

Hewett, T.E., Myer, G.D., Ford, K.R. (2004). Decrease in neuromuscular control about the knee with maturation in female athletes. JBJS, 86 (8), 1601-1608.

Hollings, S.C., Hume, P.A., Hopkins, W.G. (2014). Relative-age effect on competition outcomes at the World Youth and World Junior Athletics Championships. European Journal of Sport Science, 14 (sup1), S456-S461.

Hopkins, W.G. (2006). A new view of statistics: A scale of magnitudes for effect sizes. Retrieved January, 9, 2014.

Jiménez, I.P., Pain, M.T. (2008). Relative age effect in Spanish association football: Its extent and implications for wasted potential. Journal of Sports Sciences, 26 (10), 995-1003.

Kearney, P.E., Hayes, P.R., Nevill, A. (2018). Faster, higher, stronger, older: relative age effects are most influential during the youngest age grade of track and field athletics in the United Kingdom. Journal of Sports Sciences, 36 (20), 2282-2288.

Kruger, A., Pienaar, A.E. (2009). Anthropometric, physical and motor performance determinants of sprinting and long jump in 10-15 year old boys from disadvantaged communities in South Africa. South African Journal for Research in Sport, Physical Education and Recreation, 31 (2), 69-81.

Kubo, K., Kanehisa, H., Fukunaga, T. (2003). Gender differences in the viscoelastic properties of tendon structures. European Journal of Applied Physiology, 88 (6), 520-526.

Lemez, S., Fraser-Thomas, J. (2018). Retiring at 10 years of age: A discussion of the major trends in organized youth sports today and their association to relative-age-related dropout. Relative Age Effects: An International Conference, 7.

Lloyd, R.S., Oliver, J.L., Faigenbaum, A.D., Myer, G.D., Croix, M. (2014). Chronological age vs. biological maturation: implications for exercise programming in youth. The Journal of Strength \& Conditioning Research, 28 (5), 1454-1464.

Lovell, R., Towlson, C., Parkin, G., Portas, M., Vaeyens, R., Cobley, S. (2015). Soccer player characteristics in English lower-league development programmes: The relationships between relative age, maturation, anthropometry and physical fitness. PloS one, 10 (9).

McCarthy, N., Collins, D. (2014). Initial identification \& selection bias versus the eventual confirmation of talent: evidence for the benefits of a rocky road?. Journal of Sports Sciences, 32 (17), 1604-1610.

MacDonald, D.J., Baker, J. (2013). Circumstantial development: Birthdate and birthplace effects on athlete development. Conditions of Children's Talent Development in Sport, 197-208.

Milić, M. (2016). Differences in certain dimensions of anthropological status of young soccer players of different chronological, biological and training age. Sport Science, 9 (Suppl 2), 60.

Mohamed, H., Vaeyens, R., Matthys, S., Multael, M., Lefevre, J., Lenoir, M., Philippaerts, R. (2009). Anthropometric and performance measures for the development of a talent detection and identification model in youth handball. Journal of Sports Sciences, 27 (3), 257-266.

Nagy, N., Földesi, G., Sós, C., Ökrös, C. (2018). Talent Selection and Management in View of Relative Age: the Case of Swimming. Physical Culture and Sport. Studies and Research, 80 (1), 57-67.

Pandi, J.M.C. (2018). Prediction of track and field performance of young talents: A review. International Journal of Physical Education, Sports and Health, 5 (2), 205-207.

Papaiakovou, G., Giannakos, A., Michailidis, C., Patikas, D., Bassa, E., Kalopisis, V., Anthrakidis, N., Kotzamanidis, C. (2009). The effect of chronological age and gender on the development of sprint performance during childhood and puberty. The Journal of Strength \& Conditioning Research, 23 (9), 2568-2573.

Penna, E.M., Campos, B.T., Gonçalves, G.G.P., Godinho, G.H.P., Lima, C.O.V., Prado, L.S. (2018). Relative age effect and dropout causes in a multisport club setting. Is there a special reason to give up?. Motriz: Revista de Educação Física, 24 (4).

Pizzuto, F., Bonato, M., Vernillo, G., La Torre, A., Piacentini, M.F. (2017). Are the world junior championship finalists for middle-and long-distance events currently competing at international level?. International Journal of Sports Physiology and Performance, 12 (3), 316-321. 
Práxedes, A., Moreno, A., García-González, L., Pizarro, D., Del Villar, F. (2017). The relative age effect on soccer players in formative stages with different sport expertise levels. Journal of Human Kinetics, 60 (1), 167-173.

Romann, M., Cobley, S. (2015). Relative age effects in athletic sprinting and corrective adjustments as a solution for their removal. PLoS One, 10 (4).

Romann, M., Fuchslocher, J. (2014). The need to consider relative age effects in women's talent development process. Perceptual and Motor Skills, 118 (3), 651-662.

Saavedra-García, M., Gutiérrez-Aguilar, O., Sa-Marques, P., Fernández-Romero, J.J. (2016). Efecto de la edadrelativa en el atletismoespañol. Cuadernos de Psicología del Deporte, 16 (1), 275-286.

Salinero, J.J., Pérez, B., Burillo, P., Lesma, M.L. (2013). Relative age effect in european professional football. Analysis by position. Journal of Human Sport and Exercise, 8 (4), 966-973.

Sarmento, H., Anguera, M.T., Pereira, A., Araújo, D. (2018). Talent identification and development in male football: A systematic review. Sports Medicine, 48 (4), 907-931.

Sherar, L.B., Esliger, D.W., Baxter-Jones, A.D., Tremblay, M.S. (2007). Age and gender differences in youth physical activity: Does physical maturity matter?. Medicine \& Science in Sports \& Exercise, 39 (5), 830-835.

Smith, K.L., Weir, P.L., Till, K., Romann, M., Cobley, S. (2018). Relative age effects across and within female sport contexts: A systematic review and meta-analysis. Sports Medicine, 48 (6), 1451-1478.

Tanner, J.M. (1981). Growth and maturation during adolescence. Nutrition Reviews, 39 (2), 43-55.

Till, K., Cobley, S., Wattie, N., O'hara, J., Cooke, C., Chapman, C. (2010). The prevalence, influential factors and mechanisms of relative age effects in UK Rugby League. Scandinavian Journal of Medicine \& Science in Sports, 20 (2), 320-329.

Cite this anticle aS: Gioldasis, A., Bekris, E., Smirniotou, A. (2021). Relative Age Effect: A Systematic Discrimination against Biologically Younger Athletes. Central European Journal of Sport Sciences and Medicine, 3 (35), 27-40. DOI: 10.18276/ cej.2021.3-03. 